Article

\title{
Ginsenoside Re Inhibits ROS/ASK-1 Dependent Mitochondrial Apoptosis Pathway and Activation of Nrf2-Antioxidant Response in Beta-Amyloid-Challenged SH-SY5Y Cells
}

\author{
Meichen Liu, Xueyuan Bai, Shiting Yu, Wenxue Zhao, Juhui Qiao, Ying Liu, Daqing Zhao, \\ Jiawen Wang * and Siming Wang * \\ Jilin Ginseng Academy, Changchun University of Chinese Medicine, Changchun 130117, China \\ * Correspondence: wangjiawen1229@163.com (J.W.); 1wsm126030@163.com (S.W.)
}

Received: 24 June 2019; Accepted: 18 July 2019; Published: 24 July 2019

\begin{abstract}
Accumulation of amyloid- $\beta(A \beta)$, which results in the formation of senile plaques that cause oxidative damage and neuronal cell death, has been accepted as the major pathological mechanism of Alzheimer's disease (AD). Hence, inhibition of A $\beta$-induced oxidative damage and neuronal cell apoptosis represents the effective strategies in combating AD. Ginsenoside Re (Re) has pharmacological effects against $\mathrm{A} \beta$-induced neurotoxicity. However, its molecular mechanism remains elusive. The present study evaluated the effect of Re against $A \beta$-induced cytotoxicity and apoptosis in SH-SY5Y cells, and investigated the underlying mechanism. We demonstrate that Re inhibits the $A \beta$-triggered mitochondrial apoptotic pathway, as indicated by maintenance of mitochondrial functional, elevated $\mathrm{Bcl}-2 / \mathrm{Bax}$ ratio, reduced cytochrome $\mathrm{c}$ release, and inactivation of caspase-3/9. Re attenuated $A \beta$-evoked reactive oxygen species (ROS) production, apoptosis signal-regulating kinase 1 (ASK1) phosphorylation, and JNK activation. ROS-scavenging abrogated the ability of Re to alter ASK-1 activation. Simultaneously, inhibition of JNK abolished Re-induced Bax downregulation in A $\beta$-challenged SH-SY5Y cells. In addition, Re enhanced activation of the nuclear factor-E2-related factor 2 (Nrf2) in A $\beta$-induced SH-SY5Y cells. Knockdown of Nrf2 by small interfering RNA targeting Nrf2 abolished the protective effect of Re. Our findings indicate that Re could be a potential therapeutic approach for the treatment of AD.
\end{abstract}

Keywords: Alzheimer's disease; $\beta$-amyloid; ginsenoside Re; mitochondria; oxidative stress

\section{Introduction}

Alzheimer's disease (AD), which affects millions of older adults worldwide, is the most prevalent chronic neurodegenerative disorder [1]. The number of patients with AD is rapidly increasing such that by 2050, the number of individuals with AD will exceed 130 million worldwide [2]. Increased $\beta$-amyloid $(\mathrm{A} \beta)$ plaques in the brain are regarded as the pathological hallmark of AD [3]. The self-assembling of $A \beta$ into neurotoxic aggregates is considered a central event in the pathogenesis of $\mathrm{AD}$ (amyloid hypothesis). Several adverse factors are known to contribute to $\mathrm{A} \beta$ aggregation. Current research indicates that abnormal interactions with model membranes have been evidenced to foster $\mathrm{A} \beta$ aggregation [4]. Mislocated metal ions as $\mathrm{Cu}(\mathrm{II})$, which in physiological conditions contribute to the stability of native proteins, may accelerate reactive oxygen species (ROS) production, protein misfolding, and aggregation [5]. Although the pathogenesis of AD remains largely unclear, the amyloid hypothesis remains dominant. However, there is no treatment available that substantially delays the onset or progression of AD [6-8]. Thus, treating AD is the single biggest unmet medical need in neurology and the development of an effective therapeutic intervention is crucial for public health. 
Apoptosis is a physiological response that occurs during the development of the nervous system [9]. Aberrant apoptosis plays a key role in the progression of several neurodegenerative disorders [10]. Autopsy of AD patients revealed large amounts of neuronal apoptosis in the brain, and $A \beta$-induced neuronal apoptosis has been recapitulated in various models of AD [11-13]. Notably, mitochondria are at the center stage in human neurodegenerative diseases. Accumulating evidence has implicated mitochondria in A $\beta$-induced neuronal apoptosis. Indeed, defects in mitochondria trigger oxidative stress, which is the primary event in AD pathology [14]. Defective mitochondria inhibit the production of ATP and increase the production of ROS [15]. Accumulation of ROS leads to oxidative damage, which accelerates $A \beta$ accumulation, activates the mitochondrial permeability transition pore, increases cytochrome c (cyt c) release, and subsequently induces mitochondria-related apoptotic pathways [16]. Apoptosis signal-regulating kinase 1 (ASK-1), a key regulator of the mitochondria-related apoptotic pathway, is highly sensitive to ROS and plays a pivotal role in neuroprotection by regulating the Bcl-2 family of proteins $[17,18]$. Apart from this, the neuronal membranes are found to be rich in polyunsaturated fatty acids, which are highly susceptible to ROS. Accumulation of ROS result in biochemical alteration in bimolecular components, further linked to a variety of potential toxic mechanism associated with $\mathrm{AD}$ [19-21]. Although it remains unclear whether oxidative stress is a major cause or merely a consequence of mitochondrial dysfunction associated with $\mathrm{AD}$, supplementation with antioxidants is reportedly beneficial, especially in the early stages of $\mathrm{AD}[22,23]$. Thus, pharmacological inhibition of oxidative stress and regulation of mitochondria-related apoptotic pathways in AD pathology have sparked interest as therapeutic targets.

To this aim, several natural antioxidants as silymarin, bacoside- $\mathrm{A}$, and resveratrol have evidenced antioxidant effects and are currently under clinical investigation [24-27]. Among natural antioxidants, Panax ginseng C.A. Meyer (P. ginseng) is an herb that has been used in China for thousands of years. $P$. ginseng has excellent antioxidant effects, as well as demonstrated pharmacological effects in the central nervous system [28,29]. Ginsenosides are the major active components responsible for the multiple activities of ginseng [30]. Ginsenoside Re, one of the most important active components of ginsenosides, possesses antioxidant and antioxidant-related properties in various cell types [31-33]. Previous studies reported that ginsenoside Re exhibited direct neuroprotective effects against $A \beta$ stimulation. Indeed, ginsenoside Re significantly reduced $A \beta 1-40$ and $A \beta 1-42$ levels in cell-based assays, and its oral administration significantly reduced $A \beta$ levels in the brains of Tg2576 mice [34]. Thus, ginsenoside Re may provide a potential means of slowing the progression of $\mathrm{AD}$, although the underlying cellular and molecular mechanisms are still unclear. We speculated that the neuroprotective activity of ginsenoside Re might be attributable to its dual antioxidant and anti-apoptotic activities. To address this hypothesis, we characterized the neuroprotective activities of ginsenoside Re in A $\beta$-induced neurotoxicity in SH-SY5Y cells, and investigated involved signaling pathways. We first demonstrated that the neuroprotective activity of ginsenoside Re was closely associated with the regulation of ROS-dependent ASK-1/c-Jun N-terminal kinases (JNK)/Bax apoptosis pathways. We also demonstrated that ginsenoside Re activated the endogenous antioxidant response pathways by activating Nrf2 and its target genes against $A \beta$-induced oxidative stress.

\section{Results}

\subsection{Ginsenoside Re Protected SH-SY5Y Cells against A 25 -35-Induced Cytotoxicity}

Ginsenoside Re reportedly shows neuroprotective effects in vitro and in vivo [34]. Thus, we used the CCK-8 method to quantify cytoprotection elicited by ginsenoside Re. As shown in Figure 1b, without A $325-35$ treatment, ginsenoside Re $(75 \mathrm{uM})$ showed no toxicity to SH-SY5Y cells. When treated with $25 \mathrm{uM} \mathrm{A} \beta 25-35$, the cell viability significantly decreased. In the range $(20,25$, and $30 \mathrm{uM})$, ginsenoside Re has a promotive effect on neuronal cell survival. $25 \mu \mathrm{M}$ ginsenoside Re reached a peak with a $43.51 \%$ increase compared with $\mathrm{A} \beta$-induced alone. Therefore, $25 \mu \mathrm{M}$ was chosen as the maximum concentration of ginsenoside Re for use throughout subsequent experiments. 


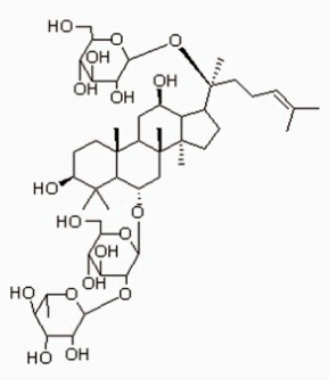

(a)
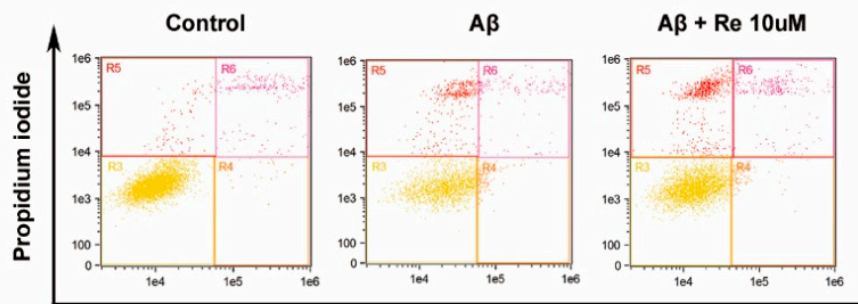

FITC-Annexin V

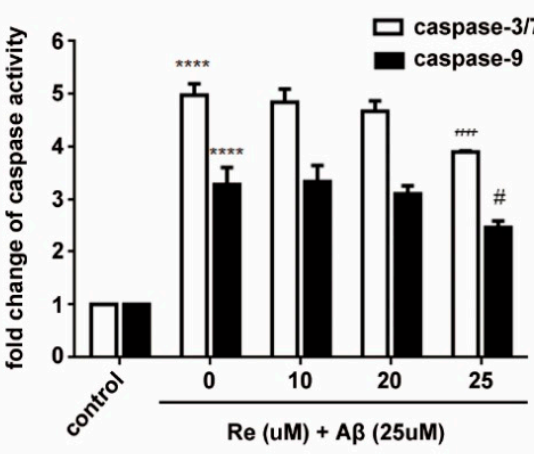

(e) (d)

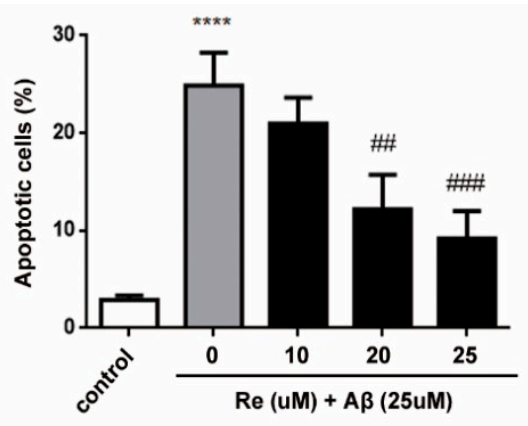

(c)

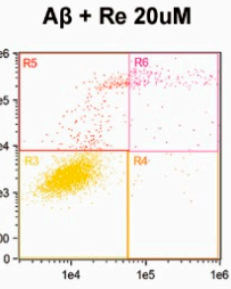

$A \beta+\operatorname{Re} 25 u M$

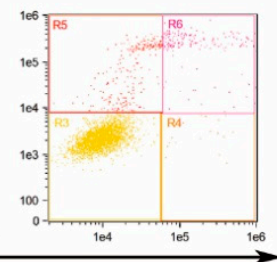

tea

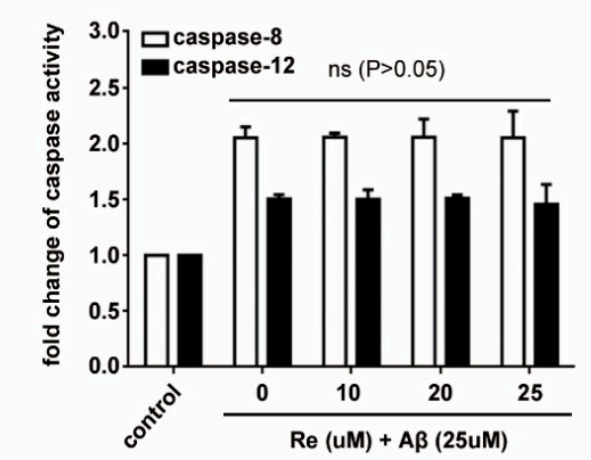

(f)

Figure 1. Protective effects of ginsenoside Re against A $\beta 25-35$-induced cell damage. (a) Chemical structure of ginsenoside Re (molecular formula: C48H82O18; molecular weight: 947.12); (b) SH-SY5Y cells were co-treated with ginsenoside Re and A $\beta$ for $24 \mathrm{~h}$. Cell viability was determined by CCK- 8 assays. Bar diagrams showing percentage of survival cells; (c) bar diagrams showing percentage of apoptosis; (d) annexin V/FITC-PI staining and flow cytometric analysis of apoptosis; (e) caspase-3/7 and caspase- 9 activity were assessed by fluorometric and colorimetric assay, respectively; and (f) caspase- 8 and caspase-12 activity were assessed by fluorometric assay. ${ }^{* * * *} p<0.0001$ versus control; ${ }^{\#} p<0.05$, \#\# $p<0.01, \# \#<0.001$ versus $\mathrm{A} \beta$ treatment alone.

As $\mathrm{A} \beta$-induced apoptosis is a key pathologic event in AD [12], we next investigated whether ginsenoside Re inhibited A $\beta$-induced apoptosis of SH-SY5Y cells. Results of Annexin V-FITC/PI staining and flow cytometry revealed that apoptotic rates were decreased from $25.88 \%$ to $10.23 \%$ compared with A $\beta$-induced SH-SY5Y cells (Figure 1c,d). The effect of ginsenoside Re on apoptotic markers was further examined. Ginsenoside Re significantly reduced A $\beta$-induced increases in caspase-3/7 activity and decreases in caspase- 9 activity, but did not significantly affect caspase- 8 or caspase- 12 activities (Figure 1e,f). These results suggest that the mitochondrial pathway (intrinsic), rather than the endoplasmic reticulum or death receptor pathway (extrinsic), contributes to the neuroprotective effect of ginsenoside Re. 
2.2. Ginsenoside Re Alleviated Mitochondrial Dysfunction and Prevented the Mitochondria-Mediated Apoptotic Pathway in SH-SY5Y Cells after A 25-35 Exposure

We demonstrated that ginsenoside Re protected SH-SY5Y cells against A $\beta$-induced apoptosis through the mitochondrial pathway. Thus, we next investigated the role of ginsenoside Re in mitochondrial dysfunction and downstream mitochondria-mediated apoptosis-related proteins in response to $A \beta$ exposure.

Collapse of MMP (mitochondrial membrane potential) is an early step in the induction of mitochondrial dysfunction that can subsequently induce apoptosis [35]. Our results demonstrated that $A \beta$-exposure resulted in the loss of MMP, but ginsenoside Re prevented this effect in $A \beta$-treated SH-SY5Y cells (Figure 2a). In addition, ginsenoside Re rescued the reduction of ATP production in A $\beta$-treated SH-SY5Y cells (Figure 2b).

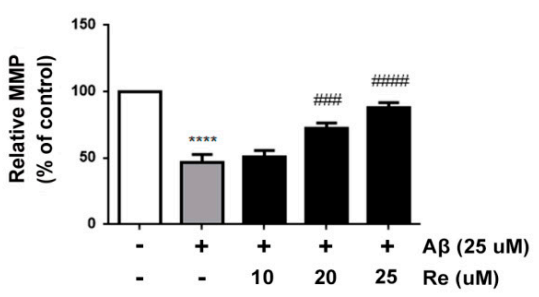

(a)
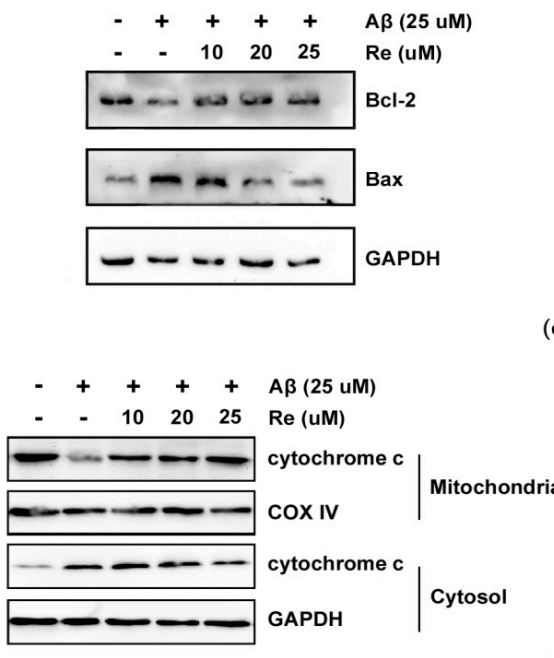

(d)

(c)

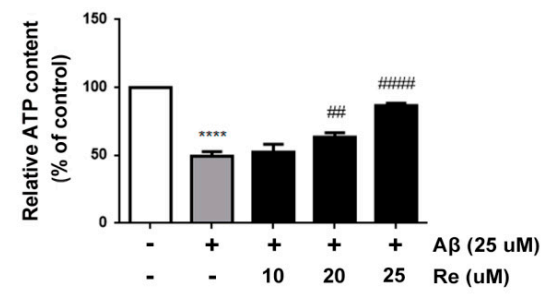

(b)
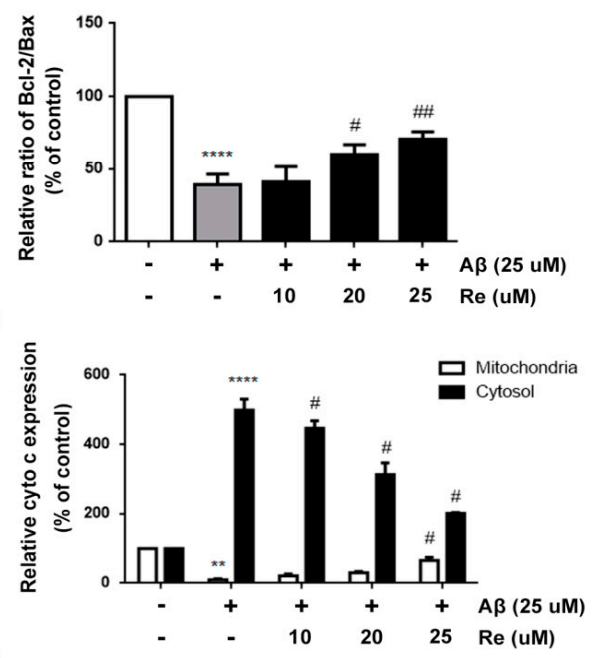

Figure 2. Ginsenoside Re alleviated mitochondrial dysfunction and prevents mitochondria mediated apoptotic pathway after A $\beta$ 25-35 exposure in SH-SY5Y cells. (a) The loss of MMP in SH-SY5Y cells; (b) the relative ATP content in SH-SY5Y cells; (c) the protein expression levels of Bcl-2 and Bax in SH-SY5Y cells were detected by western blot analysis; (d) western blot analysis to detect cytochrome c levels in mitochondrial fraction and cytosolic fraction of SH-SY5Y cells. ${ }^{* *} p<0.01,{ }^{* * * *} p<0.0001$ versus control; ${ }^{\#} p<0.05,{ }^{\# \#} p<0.01,{ }^{\# \#} p<0.001,{ }^{\# \# \#} p<0.0001$ versus $\mathrm{A} \beta$ treatment alone.

As Bax coordinates with Bcl-2 to trigger the mitochondrial apoptotic pathway [36], we next examined whether ginsenoside Re altered expression of Bcl-2 or Bax. The results showed that ginsenoside Re pre-treatment increased the ratio of Bcl-2/Bax compared with A $\beta$-induced SH-SY $5 Y$ cells (Figure 2c). As Bcl-2/Bax induces release of cyt c from mitochondria into the cytoplasm when mitochondrial apoptosis occurs, we analyzed cyt c release by western blot analysis [37]. Our results showed increased cytosolic cyt c levels increased in A $325-35$-induced SH-SY5Y cells. Consistent with expectations, ginsenoside Re pre-treatment prevented cyt c release from mitochondria into the cytosol (Figure 2d). These results demonstrated that the neuroprotective effect of ginsenoside Re is accompanied by the protection of mitochondrial dysfunction and prevention of the mitochondria-mediated apoptotic pathway. 


\subsection{Ginsenoside Re Inhibited A $\beta$-induced ASK-1/JNK Activation in a ROS-Dependent Manner}

Ginsenoside $\operatorname{Re}$ dramatically attenuated $A \beta$-induced Bax upregulation in a concentration-dependent manner; thus, we further investigated its upstream mechanism. Bax expression is regulated by the ASK-1/JNK pathway, whose activation contributes to A $\beta$-induced apoptosis [38,39]. Thus, we hypothesized that the ASK-1/JNK pathway is involved in the neuroprotective effects of ginsenoside Re. We examined phosphorylated and total protein levels of ASK-1 and JNK in A $\beta$-induced SH-SY5Y cells treated with ginsenoside Re by western blot assay. As shown in Figure 3a,b, $25 \mu \mathrm{M}$ ginsenoside Re obviously attenuated $A \beta$-induced phosphorylation of ASK-1 and JNK.
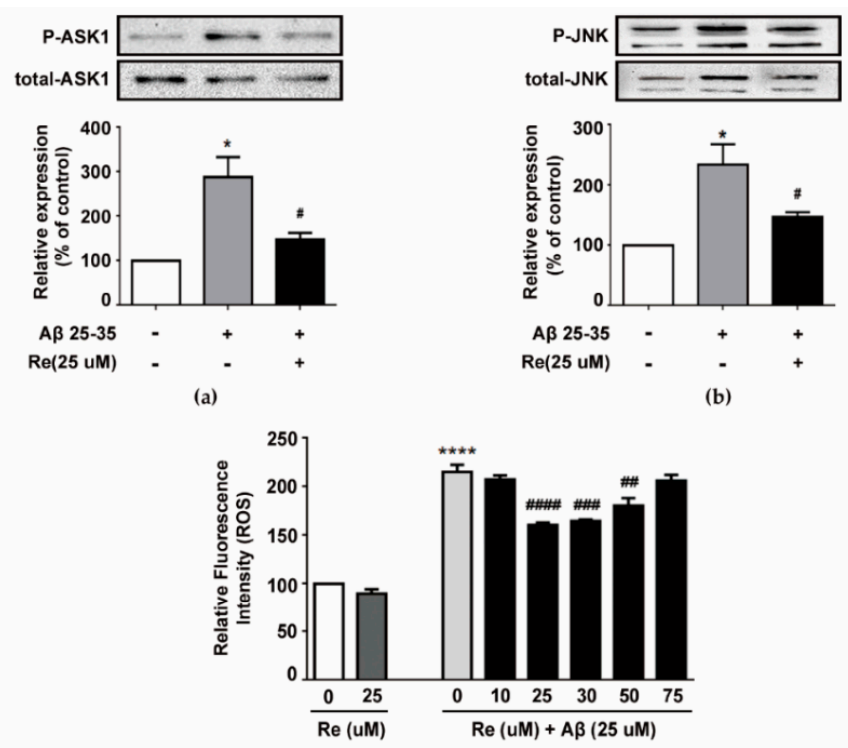

(c)
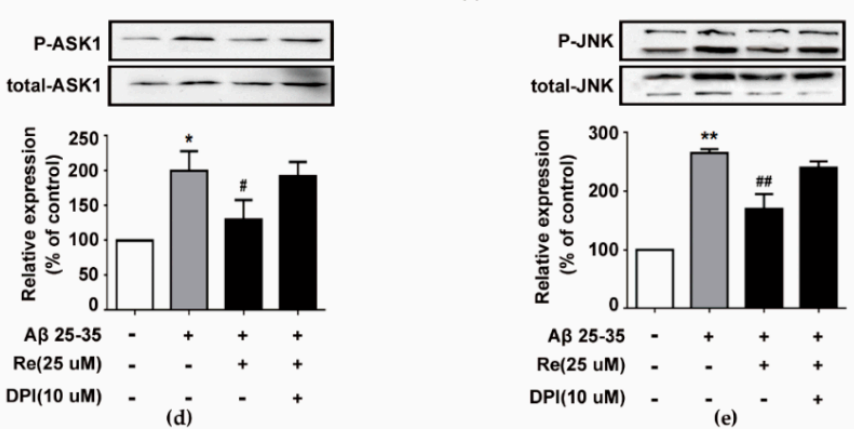

Figure 3. Inhibition of A $\beta$-induced ASK1/JNK pathway by ginsenoside Re is dependent on attenuation of $A \beta$-induced excessive reactive oxygen species (ROS) generation. (a) Level of p-ASK1 was analyzed by western blot and the band intensity of p-ASK1 was quantified by densitometry and normalized to total ASK1; (b) level of p-JNK was analyzed by western blot and the band intensity of p-JNK was quantified by densitometry and normalized to total JNK; (c) intracellular ROS were estimated using the fluorescent probe DCFH-DA by Amnis flow cytometry; (d,e) SH-SY5Y cells were pre-treated with or without DPI (NADPH oxidase inhibitor diphenyleneiodonium) for $50 \mathrm{~min}$ and then treated with Re in the presence or absence of A $\beta$ for $24 \mathrm{~h}$. Level of $\mathrm{p}-\mathrm{JNK}$ and p-ASK1 was analyzed by western blot. ${ }^{*} p<0.05,{ }^{* *} p<0.01,{ }^{* * * *} p<0.0001$ versus control; ${ }^{\#} p<0.05$, \#\# $p<0.01$, \#\#\# $p<0.001$, \#\#\# $p<0.0001$ versus $A \beta$ treatment alone.

Previous reports suggested that A $\beta$-induced ASK- 1 activation and apoptosis is mediated by ROS [40]. Moreover, excessive ROS is generated in A $\beta$-challenged cells. Therefore, we examined whether ginsenoside Re modulated ROS production in A $\beta$-challenged SH-SY5Y cells. Our data showed that cells exposed to $A \beta$ for $24 \mathrm{~h}$ exhibited an approximately two-fold increase in intracellular ROS, but 
ginsenoside Re treatment prevented ROS elevation in a dose-dependent manner (Figure 3c). Moreover, ginsenoside Re inhibited ASK-1/JNK phosphorylation in a ROS-dependent manner (Figure 3d,e).

\subsection{Inhibition of ROS-Dependent ASK-1/JNK Signaling Attenuated the Neuroprotective Effects of Ginsenoside Re}

To further confirm the roles of ROS-dependent ASK-1/JNK signaling pathway in the neuroprotective effect of ginsenoside Re, we tested whether pathway inhibitors could affect the cytoprotective effect of ginsenoside Re in A $\beta$-challenged SH-SY5Y cells. Our results revealed that $25 \mu \mathrm{M}$ Re yielded about $30.6 \%$ neuroprotection compared with $\mathrm{A} \beta$ treatment alone, similar to the result shown in Figure 1a. However, addition of DPI (NADPH oxidase inhibitor diphenyleneiodonium) or sp600125 abolished the neuroprotective effect of Re (Figure 4a).

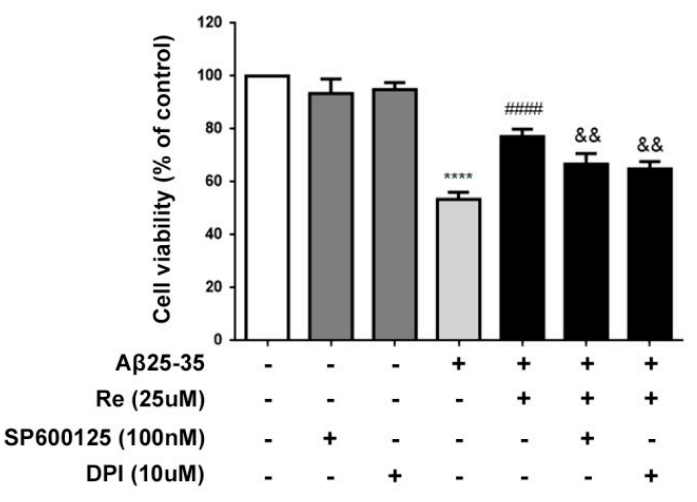

(a)

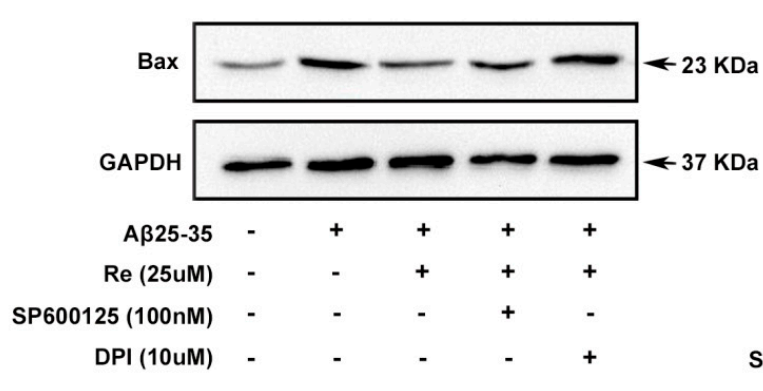

(b)

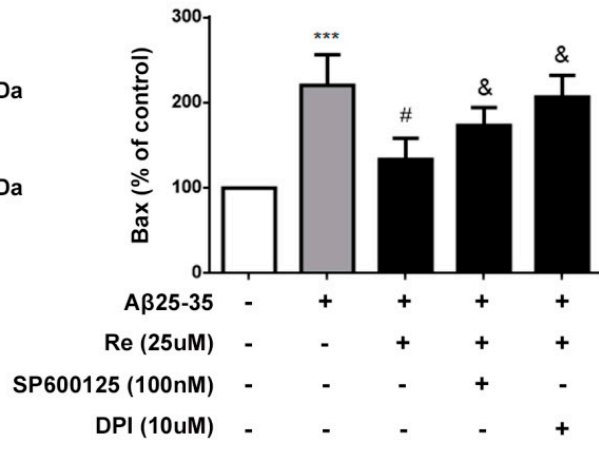

(c)

Figure 4. The neuroprotective effect of ginsenoside Re is dependent of ROS-dependent ASK1/JNK signaling pathway. (a) SH-SY5Y cells were pre-incubated with or without $100 \mathrm{nM}$ sp600125 or $10 \mathrm{uM}$ DPI for $50 \mathrm{~min}$ and then treated with $25 \mu \mathrm{M}$ Re and with or without A $\beta 25-35$ for $24 \mathrm{~h}$. Cell viability was detected by CCK-8 assay; $(\mathbf{b}, \mathbf{c})$ western blot analysis to detect level of Bax. The band intensity of Bax was quantified by densitometry and normalized to GAPDH. ${ }^{* * *} p<0.001,{ }^{* * * *} p<0.0001$ versus control; ${ }^{\#} p<0.05,{ }^{\# \# \# ~} p<0.0001$ versus A $\beta$ treatment alone; ${ }^{\&} p<0.05$, \&\& $p<0.01$ versus the cells treated with $\mathrm{A} \beta$ and $25 \mathrm{uM}$ Ginsenoside Re.

We next investigated whether these pathway inhibitors could affect Bax protein levels. Our results showed that ginsenoside Re-mediated inhibition of Bax expression in A $\beta$-challenged SH-SY5Y cells was dependent on ROS-dependent ASK-1/JNK signaling (Figure 4b,c).

\subsection{Ginsenoside Re Attenuated A $\beta$-Induced Cellular Oxidative Stress by Activating Nrf2-Antioxidant Signaling}

Ginsenoside Re reduced ROS levels and, thus, protected SH-SY5Y cells against A $\beta$-induced cytotoxicity. As such, we further investigated its antioxidative mechanisms. Nrf2 is recognized 
to regulate the expression of antioxidant genes that protect against oxidative damage triggered by injury. Thus, we next investigated involvement of the Nrf2 pathway in the antioxidative activity of ginsenoside Re.

Our results revealed that $25 \mu \mathrm{M}$ ginsenoside Re treatment markedly increased the level of Nrf2 protein in the nucleus and elicited a concomitant decrease in the cytoplasm $(p<0.01, p<0.05$, Figure 5a,b). Translocation of activated Nrf2 from the cytosol into nuclei induced the transcription of many Nrf2-regulated antioxidant enzymes. The effects of ginsenoside Re on mRNA expression of GCLc, HO-1, and NQO1 were determined, as they are directly linked to the Nrf2-mediated antioxidative defense response. GCLc, HO-1 and NQO1 gene expression was induced $24 \mathrm{~h}$ after A $\beta$ administration and remained increased at $48 \mathrm{~h}$ post-treatment. Ginsenoside Re treatment further increased this expression. The effect of ginsenoside Re was even greater at $48 \mathrm{~h}$ than observed at $24 \mathrm{~h}$ in the presence of $\mathrm{A} \beta$ ( $p<0.05$ versus cells treated with A $\beta 25-35$ alone; Figure $5 c$ ). Consistently, the content of GSH and activities of SOD and Gpx were significantly increased by ginsenoside Re treatment $(p<0.0001$ versus control, $p<0.001, p<0.0001$ versus cells treated with A $\beta 25-35$ alone Figure $5 \mathrm{~d}$ ).

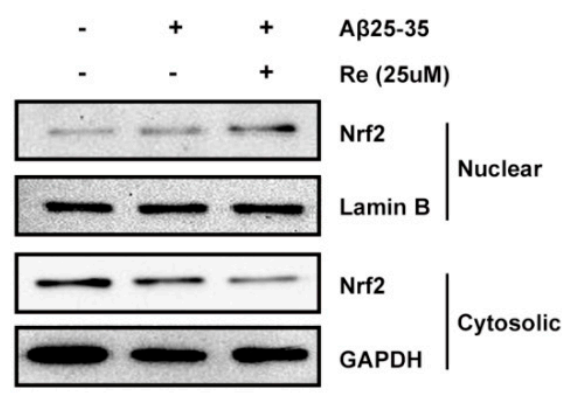

(a)

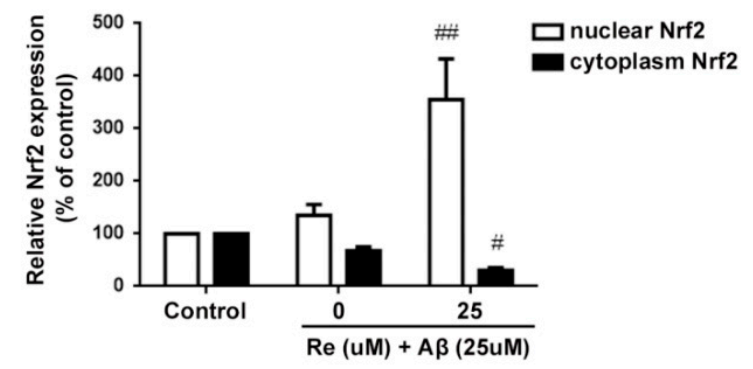

(b)

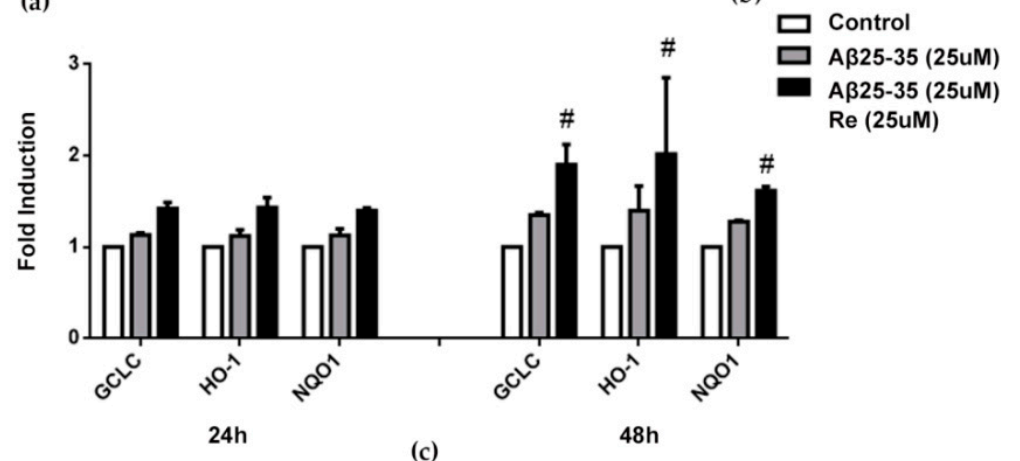

(c)
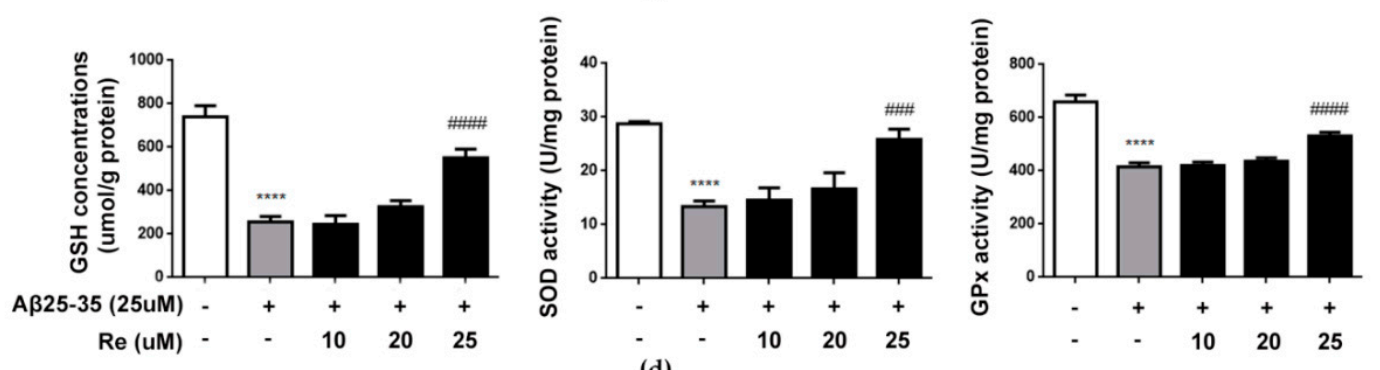

(d)

Figure 5. Ginsenoside Re induced the activation of Nrf2-antioxidant signaling in A $\beta$-induced SH-SY5Y cells. $(\mathbf{a}, \mathbf{b})$ Ginsenoside Re promoted the nuclear translocation of Nrf2 in A $\beta$-induced SH-SY5Y cells by western blot assay; (c) A $\beta$ treatment significantly induced the expression of Nrf2-mediated antioxidant response genes, including GCLc, NQO1 and HO-1 at both $24 \mathrm{~h}$ and $48 \mathrm{~h}$. Ginsenoside Re treatment potentiated this increase at both time points than $\mathrm{A} \beta$ induced alone ( $n=3$ per treatment condition); (d) the concentrations of GSH and activities of SOD and GPX in SH-SY5Y cells in different treatments were measured as described in the materials and methods ( $n=5$ per treatment condition). ${ }^{* * *} p<0.0001$ versus control; ${ }^{\#} p<0.05,{ }^{\# \#} p<0.01,{ }^{\# \# \#} p<0.001,{ }^{\# \# \#} p<0.0001$ versus $\mathrm{A} \beta$ treatment alone. 
2.6. Ginsenoside Re Alleviated AB-Induced Cytotoxicity and ROS Generation in SH-SY5Y Cells in a Nrf2-Dependent Manner

Based on the outcomes described above, we hypothesized that the protective effects of ginsenoside Re against $A \beta$-induced oxidative damage resulted from upregulation of the Nrf2 pathway. To verify this hypothesis, Nrf2 was silenced in A $\beta$-induced SH-SY5Y cells (Figure 6a). Quantification of antioxidative enzyme expression suggested that the effects of ginsenoside Re on antioxidative enzyme expression were almost abolished in Nrf2-silenced cells (Figure 6b-d).

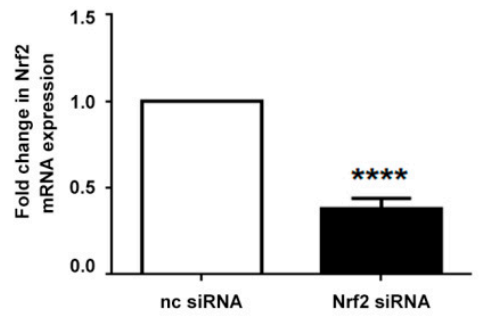

(a)

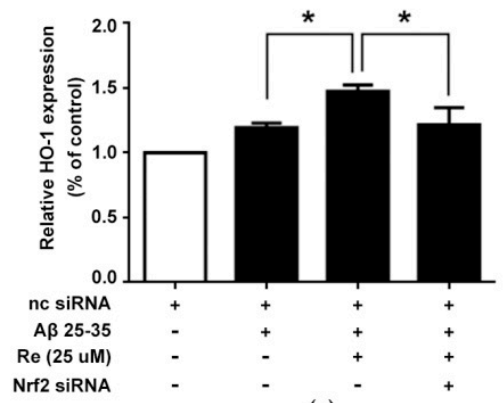

(c)

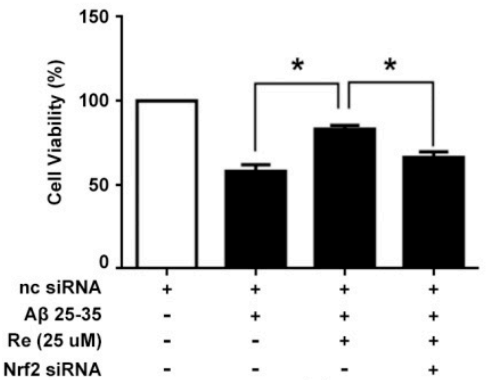

(e)

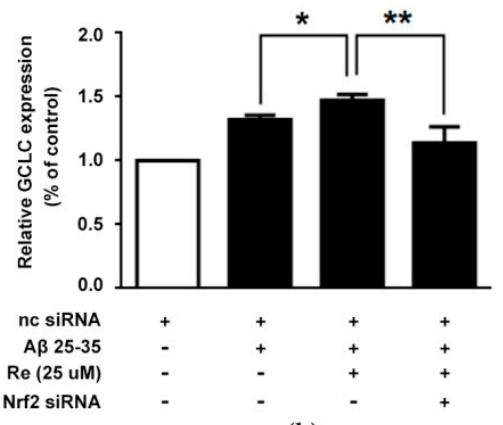

(b)
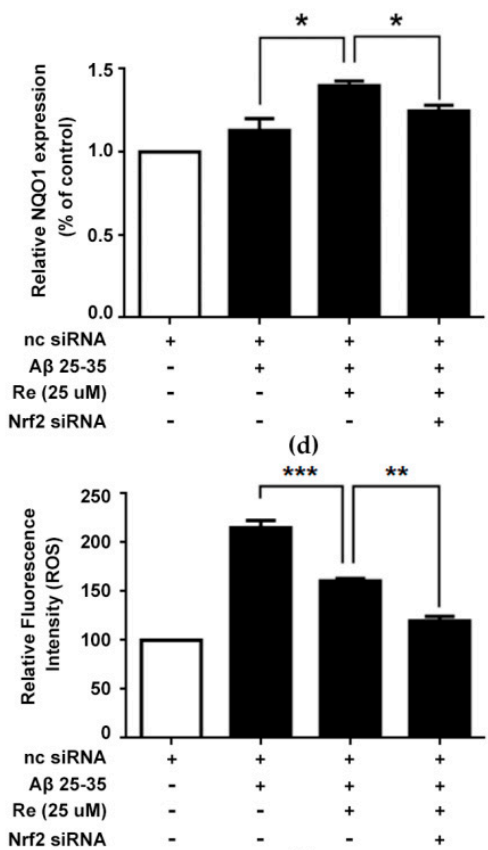

(f)

Figure 6. Ginsenoside Re alleviated A $\beta$-induced cytotoxicity and ROS generation in SH-SY5Y cells through Nrf2-dependent manner. (a) Nrf2 gene expression in negative control (nc) siRNA treatedand NRF2 siRNA treated group; (b-d) The relative mRNA expression of antioxidative enzymes were measured by qRT-PCR; (e) after transient transfection with or without Nrf2 siRNA plasmid, SH-SY5Y cells were treated with ginsenoside Re in the presence or absence of $A \beta$ for $24 \mathrm{~h}$. Cell viability was detected by CCK-8 assay; (f) intracellular ROS were estimated using the fluorescent probe DCFH-DA by flow cytometry. ${ }^{*} p<0.05,{ }^{* *} p<0.01,{ }^{* * *} p<0.001$, ${ }^{* * * *} p<0.0001$ versus control.

Additionally, we determined the effect of ginsenoside Re on A $\beta$-induced cell viability and ROS generation in Nrf2-silenced cells. Our results indicated that the cytoprotective effect on cell viability and inhibitory effect on ROS generation of ginsenoside Re were substantially impeded by Nrf2 silencing (Figure 6e,f). Collectively, these results demonstrated that ginsenoside Re-mediated cytoprotection might also be associated with targeting of the Nrf2 pathway. 


\section{Discussion}

Despite significant efforts to discover a therapeutic strategy to prevent the progression of or cure $\mathrm{AD}$, available therapy is limited to symptomatic treatments whose efficacy remains unsatisfactory at present. The results of the present study demonstrate, for the first time, that ginsenoside Re prevents $\mathrm{A} \beta$-induced mitochondrial-dependent apoptosis in SH-SY5Y cells by increasing their cellular Bcl-2/Bax ratio. The upstream mechanism was associated with attenuation of ROS-dependent proapoptotic Bax upregulation that occurs under apoptotic challenge: Ginsenoside Re inhibited Bax expression in A $\beta$-challenged SH-SY5Y cells by inhibiting JNK activity via ASK-1 inactivity. Further investigation revealed that this protective effect of ginsenoside Re was associated with activation of Nrf2-antioxidant signaling. Indeed, ginsenoside Re could induce nuclear translocation of Nrf2 to enhance the activities of several antioxidant enzymes.

Natural products, which tend to have fewer side effects, have been an important source for the discovery of novel therapeutically active compounds for AD [41]. P. ginseng, a primary herb in Traditional Chinese Medicine, has been used to treat a wide array of diseases-especially neurodegenerative diseases [42]. Ginsenosides are the most important active ingredients in P. ginseng and previous studies have shown their beneficial effects on AD [43]. Ginsenoside Re, a highly abundant active component of ginsenosides, has been found to have neuroprotective effects in a variety of animal models, including AD. Ginsenoside Re attenuated $\beta$-amyloid and serum-free-induced neurotoxicity in PC12 cells and decreased levels of $A \beta 1-40$ and $A \beta 1-42$ in the brains of Tg2576 mice [34,44]. In the present manuscript, we extended these observations by exploring the mechanism of $A \beta$-induced neuroprotection. Identifying the molecular targets of ginsenoside Re would be useful for anti-AD drug development.

It has been accepted that $A \beta$ accumulation causes mitochondria dysfunction that induces oxidative stress and excessive apoptosis, thus forming the primary event in AD pathology. As such, targeting the $A \beta$-induced mitochondria-mediated apoptotic pathway and oxidative stress may be effective therapeutic strategies to attenuate $A \beta$-induced neurotoxicity and, thus, improve neurological outcomes in AD. A $\beta 1-42$ is the major peptide constituent of amyloid plaques. However, A $\beta 25-35$ is the shortest fragment that exhibits large $\beta$-sheet fibrils and retains the toxicity of the full-length peptide. Therefore, $A \beta 25-35$ is widely used instead of the endogenous A $\beta 1-42$ fragment in AD-relevant insults in vitro [45]. In this study, $A \beta 25-35$ has been chosen as a model for full-length $A \beta$ because it retains both its physical and biological properties, while its short length readily allows derivatives to be studied. Consistent with previous reports, we observed A $325-35$ toxicity in SH-SY5Y cells. Co-treatment with ginsenoside Re rescued effects on cell viability and excessive apoptosis. Apoptotic cell death involves the activation of various caspases, which play a main role in activating and regulating the whole apoptosis process. Ginsenoside Re significantly blocked A $\beta$-induced increases in caspase- 3 and caspase-9 (mitochondria-associated caspase) activity, but failed to affect the activity of caspase- 8 (a death receptor and apoptotic signaling-related caspase) or caspase-12 (an endoplasmic reticulum-specific stress-activated caspase). These results suggest that the mitochondrial pathway plays a major role in the neuroprotective properties of ginsenoside Re against A $\beta$-induced toxicity in SH-SY5Y cells.

This function of mitochondria, which are direct targets for $A \beta$, is often disrupted in an early phase of $\mathrm{AD}$ [46]. Mitochondrial dysfunction is consistent with the reduction of MMP, which induces opening of the mitochondrial permeability transition pore, further causing release of cyt $\mathrm{c}$ into the cytosol. The results of our study demonstrated that ginsenoside Re prevented the loss of MMP, suppressed cyt c release, and promoted ATP production, indicating that ginsenoside Re protected SH-SY5Y cells against A $325-35$-induced injury through inhibition of mitochondrial dysfunction. Apoptosis is preceded by changes in regulatory proteins, such as Bcl-2 (anti-apoptotic) and Bax (pro-apoptotic), which are located in the mitochondrial membrane. The ratio of $\mathrm{Bcl}-2$ to $\mathrm{Bax}$ is a critical factor for mitochondria-mediated apoptosis. The current study found that ginsenoside Re could significantly elevate the Bcl-2/Bax ratio in $A \beta$-challenged cells. 
What is the signaling mechanism by which ginsenoside Re increases the Bcl-2/Bax ratio under apoptotic challenge? Bax is a downstream gene of ASK-1. Under normal conditions, ASK-1 is kept in an inactive form by reduced thioredoxin (Trx), which regulates ASK-1 activation in a redox-sensitive manner. Trx becomes oxidized and separates from ASK-1 when oxidative stress occurs and intracellular ROS levels increase. Subsequently, ASK-1 forms a homo-oligomeric complex, which leads to full activation of ASK-1 through autophosphorylation. Activated ASK-1 further activates JNK and upregulates Bax expression [47]. In this study, ASK-1 and JNK were significantly activated in A $325-35$-treated SH-SY5Y cells, which were probably triggered by increased intracellular ROS levels. However, activation of ASK-1 and JNK were inhibited by ginsenoside Re treatment, which is consistent with the results of ROS detection. Use of the pharmacological inhibitor DPI revealed that ginsenoside Re suppressed ASK-1 and JNK activation through a ROS-dependent mechanism. Importantly, the inhibition of apoptosis elicited by ginsenoside Re could partly be blocked by either DPI of the JNK inhibitor SP600125, indicating that ginsenoside Re can inhibit A $325-35$-induced apoptosis-promoting signals, partly by neutralizing $A \beta$-induced oxidative stress.

How does ginsenoside Re inhibit ROS generation to prevent the apoptotic effects of A $\beta$ ? Nrf2 is a stress-responsive transcriptional factor and key effector that protects cells from oxidative injury, particularly in neurodegenerative diseases [48]. Under oxidative stress conditions, Nrf2 translocates from the cytoplasm into the nucleus, whereby it subsequently induces the expression of a series of proteins, including phase II detoxifying enzymes and antioxidant proteins that can further enhance the anti-oxidative capabilities of cells [49]. Here, we demonstrated that ginsenoside Re remarkably promoted Nrf2 nuclear translocation and upregulated a set of genes encoding phase-II enzymes including HO-1, NQO1, and GCLc-consistent with increased concentrations of GSH and activities of SOD and GPx. The role of Nrf2 in A $\beta$-induced ROS is controversial. Ramsey and colleagues reported that Nrf2 is primarily located in the cytoplasm and reduced in nuclei of AD brains, suggesting that Nrf2 does not actively induce the expression of antioxidant enzymes in AD brains [50]. Sarkar and colleagues demonstrated that $A \beta 25-35$ produced significant oxidative stress and downregulated Nrf2 levels [51]. In our study, exposure to A $\beta 25-35$ caused a marginal increase in Nrf2 activation. This discrepancy might result from differences in dose and time differences, as well as the procedure used for $A \beta$ exposure. Furthermore, specific knockdown of Nrf2 using Nrf2-siRNA abolished ginsenoside Re-induced upregulation of antioxidant enzymes and almost completely disabled the neuroprotective effects of ginsenoside Re, suggesting that its anti-oxidative and neuroprotective effects are related to activation of the Nrf2 signaling pathway.

In summary, we demonstrated that ginsenoside Re exhibited strong neuroprotective activity against A $325-35$-induced neurotoxicity in SH-SY5Y cells by inhibiting ROS-dependent ASK-1/JNK/BAX cell apoptosis and activating Nrf2/HO-1 antioxidant pathways (Figure 7). These data support a potential role for ginsenoside Re in the prevention and treatment of AD. Nevertheless, the underlying mechanisms are certainly more complex than described here. For example, our results do not exclude other potential mechanisms involved in ginsenoside Re activation of Nrf2. Moreover, while we acknowledge that in vitro models may not be clinically relevant, the present results suggest that ginsenoside Re may be a promising candidate for the treatment of AD. 


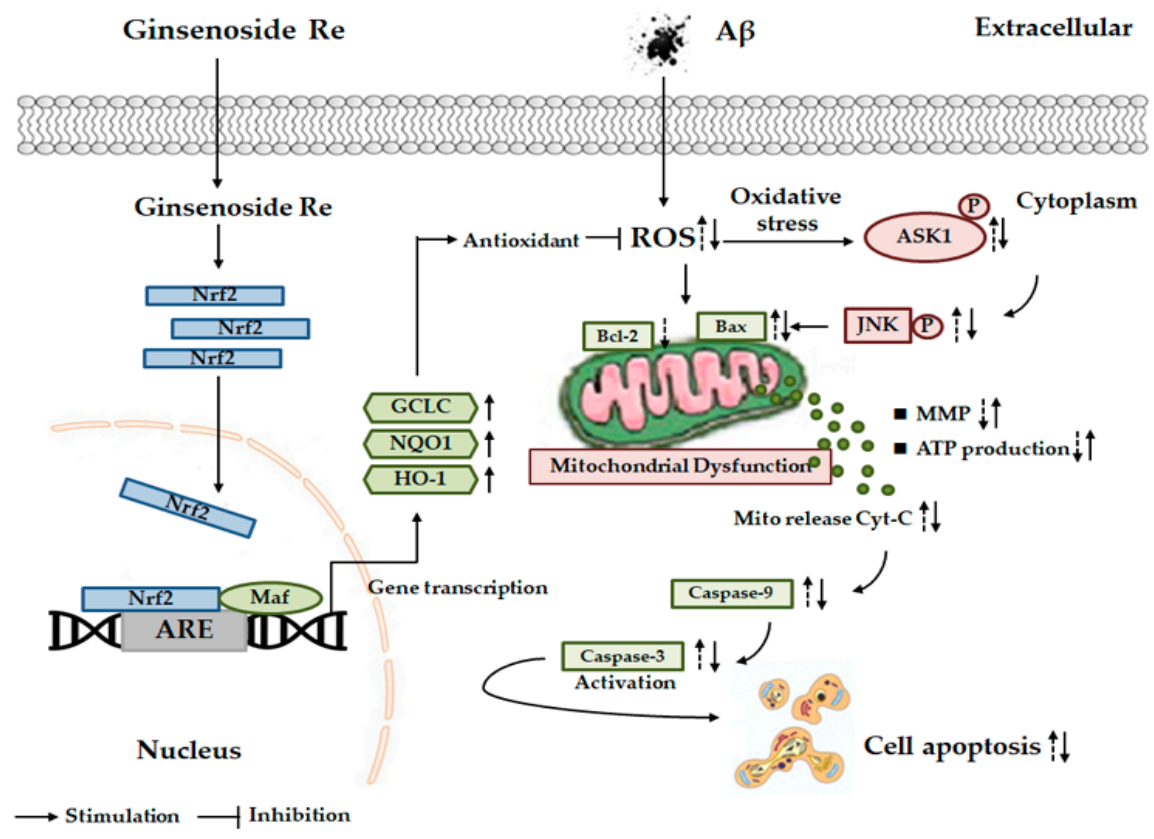

Figure 7. Scheme summarizing the protection of A $325-35$-induced SH-SY5Y cell mitochondrial dysfunction by ginsenoside Re via inhibits ROS/ASK-1 dependent mitochondrial apoptosis pathway and activation of Nrf2-antioxidant response pathway.

\section{Materials and Methods}

\subsection{Drug Preparation}

Ginsenoside Re (purity $\geq 98 \%$ ) was purchased from the Chengdu Must Bio-Technology Co., Ltd. (Sichuan, China). The molecular structure of ginsenoside Re is shown in Figure 1a.

A $\beta 25-35$ (A $\beta$ ) (Sigma, St. Louis, MO, USA) was diluted to $1 \mathrm{mM}$ in dimethylsulfoxide, incubated with constant oscillation for seven days at $37^{\circ} \mathrm{C}$ to induce aggregation, and then stored at $-20{ }^{\circ} \mathrm{C}$ until use. To prepare for use, it was further diluted to $25 \mu \mathrm{M}$ in culture medium.

\subsection{Cell Culture}

SH-SY5Y human neuroblastoma cells (purchased from ATCC (Rockville, MD, USA)) were cultured in DMEM/F12 media supplemented with $10 \%$ fetal bovine serum and $1 \%$ penicillin-streptomycin at $37^{\circ} \mathrm{C}$ with $5 \% \mathrm{CO}_{2}$. The medium was changed every other day, and cells were plated at an appropriate density according to each experimental scale.

\subsection{Analysis of Cell Viability}

Cell viability was analyzed with a CCK-8 kit (Dojindo Laboratories, Kumamoto, Japan) according to the manufacturer's instructions. SH-SY5Y cells were seeded at $0.2 \times 105$ cells/well in 96 -well plates. After $24 \mathrm{~h}$ of incubation to allow cells to adhere, cells were co-treated with ginsenoside $\operatorname{Re}(0,5,10,20$, $25,30,50$, or $75 \mu \mathrm{M}$ ) and $25 \mu \mathrm{M} \mathrm{A} \beta$ for $24 \mathrm{~h}$. After incubation, $20 \mu \mathrm{L}$ of CCK-8 solution was added to cells and incubated for $1 \mathrm{~h}$ at $37^{\circ} \mathrm{C}$. Absorbance in each well was quantified at $450 \mathrm{~nm}$ using a microplate reader (Tecan, Salzburg, Austria).

\subsection{Inhibitor Treatment and siRNA Transfection}

In experiments involving the inhibition of JNK or ROS, sp600125 (100 nM) or DPI $(10 \mu \mathrm{M})$ was added $50 \mathrm{~min}$ prior to ginsenoside Re and/or A $325-35$ treatment. Cells were transfected with control siRNA or Nrf2 siRNA using a customized siRNA reagent system (RiboBio, Guangzhou, China) according to the manufacturer's instructions. 


\subsection{Cell Apoptosis Analysis}

Cell apoptosis was measured using an Annexin-V-FITC Apoptosis Detection Kit (BD Biosciences, San Jose, CA, USA). SH-SY5Y cells were treated as described above, harvested with $0.25 \%$ trypsin, washed twice with phosphate-buffered saline (PBS), resuspended in buffer, and incubated with $5 \mu \mathrm{L}$ Annexin V-FITC and $5 \mu \mathrm{L}$ propidium iodide (PI) for $15 \mathrm{~min}$ in the dark at room temperature. Samples were then analyzed by flow cytometry (Amnis, Seattle, WA, USA).

\subsection{Caspase Activity Assay}

Caspase activity was assayed using a Caspase-3 and Caspase-8 Assays (Promega, Madison, WI, USA), a Caspase-9 Activity Assay Kit (Biobox Biotech, Nanjing, China), and Caspase-12 Fluorometric Assay Kit (BioVision, Mountain View, CA, USA) according to the manufacturers' instructions.

\subsection{Mitochondrial Membrane Potential Analysis}

Mitochondrial membrane potential (MMP) was analyzed by flow cytometric analysis using Rhodamine 123 (Rh123; Beyotime Biotechnology, Shanghai, China). After cells were exposed to A $325-35$ with or without ginsenoside Re co-treatment, Rh123 was added to the media ( $2 \mu \mathrm{M}$ final concentration) at $37^{\circ} \mathrm{C}$ for $30 \mathrm{~min}$ in the dark. After incubation, cells were detached using trypsin, centrifuged at $125 \times g$ for $5 \mathrm{~min}$, and resuspended in PBS. Amnis flow cytometry was used for detection.

\subsection{Measurement of Cellular ATP Content}

Levels of ATP in cells were determined with an ATP assay kit (Beyotime Biotechnology, Shanghai, China). Briefly, after washing with PBS, cells were lysed and centrifuged. Subsequently, $100 \mu \mathrm{L}$ of ATP detection working solution was added to the supernatant, and the chemiluminescence of samples was measured according to the manufacturer's instructions.

\subsection{Intracellular ROS Generation Detection}

Intracellular ROS was monitored using the fluorescent probe 2,7-dichlorofluorescein diacetate (DCFH-DA; Invitrogen, Carlsbad, CA, USA) as described previously [52].

\subsection{Oxidative Stress Assays}

Oxidative stress was assessed by measuring glutathione (GSH) levels and the activities of superoxide dismutase (SOD) and glutathione peroxidase (GPx). Supernatant protein concentrations were measured using a BSA kit (Beyotime Biotechnology). Levels of GSH and activities of SOD and GPx were measured using appropriate kits purchased from Beyotime Biotechnology according to the manufacturer's instructions.

\subsection{Reverse-Transcription and Real-Time PCR}

Total RNA was extracted with TRIzol reagent (Invitrogen) according to the manufacturer's instructions. Reverse transcription was performed using a PrimeScript RT reagent kit (Takara Biotechnology, Dalian, China). Real-time PCR was performed in a CFX 96 Connect $^{\mathrm{TM}}$ Optics Module (Bio-Rad Laboratories, Hercules, CA, USA) using SYBR Green PCR Master Mix (Takara Biotechnology). Aliquots of cDNA were used for PCR using primer sets specific to Nrf2, GCLC, HO-1 and NQO1, and GAPDH as a control. Primers were as follows: Nrf2: 5'-AGCGACGGAAAGAGTATGA-3', 5'-TGGGAGTAGTTGGCAGAT-3'; GCLC: 5'-TTGTTATGGCTTTGAGTG-3' , 5'-TCTGAGTTTGGAGGAGGG-3'; HO-1: 5'-AATGGTTCAGG CAACAGGG-3' , 5'-CTCCAGCAGTATGAGCAAAGTA-3'; NQO1: 5'-TGGTTTGAGCGAGTGTTC-3', 5'-TATTCTCCAGGCGTTTCT-3'; GAPDH: 5'-GGTGAAGGTCGGAGTCAACGGA-3' 5' $^{\prime}$-GAGGGAT CTCGCTCCTGGAAGA- $3^{\prime}$. Data were analyzed according to the $2^{-\Delta \Delta \mathrm{ct}}$ method, as previously described [53]. 


\subsection{Protein Extraction and Western Blotting}

After treatments, cells were lysed with ice-cold RIPA lysis buffer (Beyotime Biotechnology) containing protease inhibitors. Total protein concentration was determined using a BSA kit. For detection of cyt c, mitochondrial, and cytosolic fractions were prepared using a Mitochondria/Cytosol Fractionation kit (Abcam, Cambridge, UK). For detection of Nrf2 nuclear transfer, a NE-PER ${ }^{\mathrm{TM}}$ Nuclear and Cytoplasmic Extraction Reagents kit (Thermo Scientific, Waltham, MA, USA) was used. Western blotting was conducted as previously described [54]. Antibodies against Bcl-2, Bax, cytochrome c, Nrf2, p-JNK, JNK, p-ASK-1, ASK-1, GAPDH, Lamin B, and COX IV were supplied by Cell Signaling Technology (Danvers, MA, USA) or Abcam. Secondary antibodies were obtained from Cell Signaling Technology or Proteintech (Chicago, IL, USA).

\subsection{Statistical Analysis}

Statistical analysis was performed using Prism 6.0 software (GraphPad Software, San Diego, CA, USA). Data are expressed as mean \pm standard deviation (SD) from at least three independent experiments. Statistical analysis was performed using a one-way analysis of variance (ANOVA) test followed by a Tukey post-hoc test, ${ }^{*} p<0.05,{ }^{* *} p<0.01,{ }^{* * *} p<0.001,{ }^{* * * *} p<0.0001$ versus control;

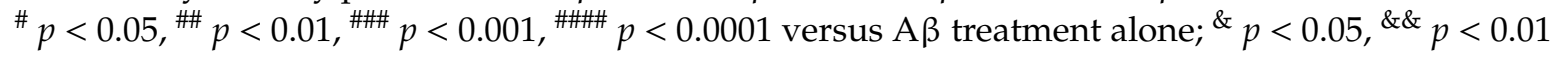
versus the cells treated with $A \beta$ and $25 \mathrm{uM}$ Ginsenoside Re.

Author Contributions: Conceptualization, M.L. and X.B.; Methodology, M.L.; Validation, S.Y., W.Z., J.Q. and Y.L.; Formal Analysis, M.L.; Investigation, M.L. and X.B.; Resources, J.W.; Writing-Original Draft Preparation, M.L.; Writing-Review and Editing, J.W. and S.W.; Supervision, D.Z.; Project Administration, D.Z.; Funding Acquisition, D.Z. and M.L.

Funding: This research was funded by grants from the National Natural Foundation of China, grant number 81703663 and the National Key Research and Development program of China, grant number 2017YFC1702104.

Acknowledgments: We thank Liwen Bianji, Edanz Group China (www.liwenbianji.cn/ac), for editing the English text of a draft of this manuscript.

Conflicts of Interest: The authors declare no conflict of interest.

\section{References}

1. Scheltens, P.; Blennow, K.; Breteler, M.M.B.; de Strooper, B.; Frisoni, G.B.; Salloway, S.; Van der Flier, W.M. Alzheimer's disease. Lancet 2016, 388, 505-517. [CrossRef]

2. Shah, H.; Albanese, E.; Duggan, C.; Rudan, I.; Langa, K.M.; Carrillo, M.C.; Chan, K.Y.; Joanette, Y.; Prince, M.; Rossor, M.; et al. Research priorities to reduce the global burden of dementia by 2025. Lancet Neurol. 2016, 15, 1285-1294. [CrossRef]

3. Busciglio, J.; Lorenzo, A.; Yeh, J.; Yankner, B.A. Beta-amyloid fibrils induce tau phosphorylation and loss of microtubule binding. Neuron 1995, 14, 879-888. [CrossRef]

4. Sciacca, M.F.M.; Tempra, C.; Scollo, F.; Milardi, D.; La Rosa, C. Amyloid growth and membrane damage: Current themes and emerging perspectives from theory and experiments on Abeta and hIAPP. Biochim. Biophys. Acta Biomembr. 2018, 1860, 1625-1638. [CrossRef] [PubMed]

5. Grasso, G.; Santoro, A.M.; Lanza, V.; Sbardella, D.; Tundo, G.R.; Ciaccio, C.; Marini, S.; Coletta, M.; Milardi, D. The double faced role of copper in $\mathrm{A} \beta$ homeostasis: A survey on the interrelationship between metal dyshomeostasis, UPS functioning and autophagy in neurodegeneration. Coord. Chem. Rev. 2017, 347, 1-22. [CrossRef]

6. Sevigny, J.; Chiao, P.; Bussiere, T.; Weinreb, P.H.; Williams, L.; Maier, M.; Dunstan, R.; Salloway, S.; Chen, T.; Ling, Y.; et al. The antibody aducanumab reduces Abeta plaques in Alzheimer's disease. Nature 2016, 537, 50-56. [CrossRef] [PubMed]

7. Bloom, G.S. Amyloid-beta and tau: The trigger and bullet in Alzheimer disease pathogenesis. JAMA Neurol. 2014, 71, 505-508. [CrossRef]

8. Barage, S.H.; Sonawane, K.D. Amyloid cascade hypothesis: Pathogenesis and therapeutic strategies in Alzheimer's disease. Neuropeptides 2015, 52,1-18. [CrossRef] 
9. Xu, T.; Niu, C.; Zhang, X.; Dong, M. beta-Ecdysterone protects SH-SY5Y cells against beta-amyloid-induced apoptosis via c-Jun N-terminal kinase- and Akt-associated complementary pathways. Lab. Investig. J. Tech. Methods Pathol. 2018, 98, 489-499. [CrossRef]

10. Radi, E.; Formichi, P.; Battisti, C.; Federico, A. Apoptosis and oxidative stress in neurodegenerative diseases. J. Alzheimers Dis. JAD 2014, 42 (Suppl. S3), S125-S152. [CrossRef]

11. Mufson, E.J.; He, B.; Nadeem, M.; Perez, S.E.; Counts, S.E.; Leurgans, S.; Fritz, J.; Lah, J.; Ginsberg, S.D.; Wuu, J.; et al. Hippocampal proNGF signaling pathways and beta-amyloid levels in mild cognitive impairment and Alzheimer disease. J. Neuropathol. Exp. Neurol. 2012, 71, 1018-1029. [CrossRef] [PubMed]

12. Liu, J.; Li, C.; Xing, G.; Zhou, L.; Dong, M.; Geng, Y.; Li, X.; Li, J.; Wang, G.; Zou, D.; et al. Beta-asarone attenuates neuronal apoptosis induced by Beta amyloid in rat hippocampus. Yakugaku Zasshi J. Pharm. Soc. Jpn. 2010, 130, 737-746. [CrossRef]

13. Zhou, Y.; Xie, N.; Li, L.; Zou, Y.; Zhang, X.; Dong, M. Puerarin alleviates cognitive impairment and oxidative stress in APP/PS1 transgenic mice. Int. J. Neuropsychopharmacol. 2014, 17, 635-644. [CrossRef] [PubMed]

14. Mancuso, M.; Coppede, F.; Murri, L.; Siciliano, G. Mitochondrial cascade hypothesis of Alzheimer's disease: Myth or reality? Antioxid. Redox Signal. 2007, 9, 1631-1646. [CrossRef] [PubMed]

15. Bosetti, F.; Brizzi, F.; Barogi, S.; Mancuso, M.; Siciliano, G.; Tendi, E.A.; Murri, L.; Rapoport, S.I.; Solaini, G. Cytochrome c oxidase and mitochondrial F1F0-ATPase (ATP synthase) activities in platelets and brain from patients with Alzheimer's disease. Neurobiol. Aging 2002, 23, 371-376. [CrossRef]

16. Devi, L.; Prabhu, B.M.; Galati, D.F.; Avadhani, N.G.; Anandatheerthavarada, H.K. Accumulation of amyloid precursor protein in the mitochondrial import channels of human Alzheimer's disease brain is associated with mitochondrial dysfunction. J. Neurosci. Off. J. Soc. Neurosci. 2006, 26, 9057-9068. [CrossRef] [PubMed]

17. Kim, H.; Oh, Y.; Kim, K.; Jeong, S.; Chon, S.; Kim, D.; Jung, M.H.; Pak, Y.K.; Ha, J.; Kang, I.; et al. Cyclophilin A regulates JNK/p38-MAPK signaling through its physical interaction with ASK1. Biochem. Biophys. Res. Commun. 2015, 464, 112-117. [CrossRef] [PubMed]

18. Qiu, C.; Wang, Y.P.; Pan, X.D.; Liu, X.Y.; Chen, Z.; Liu, L.B. Exendin-4 protects Abeta(1-42) oligomer-induced PC12 cell apoptosis. Am. J. Transl. Res. 2016, 8, 3540-3548.

19. Pilkington, A.W.T.; Donohoe, G.C.; Akhmedov, N.G.; Ferrebee, T.; Valentine, S.J.; Legleiter, J. Hydrogen Peroxide Modifies Abeta-Membrane Interactions with Implications for Abeta40 Aggregation. Biochemistry 2019, 58, 2893-2905. [CrossRef]

20. La Rosa, C.; Scalisi, S.; Lolicato, F.; Pannuzzo, M.; Raudino, A. Lipid-assisted protein transport: A diffusion-reaction model supported by kinetic experiments and molecular dynamics simulations. J. Chem. Phys. 2016, 144, 184901. [CrossRef]

21. Scollo, F.; Tempra, C.; Lolicato, F.; Sciacca, M.F.M.; Raudino, A.; Milardi, D.; La Rosa, C. Phospholipids Critical Micellar Concentrations Trigger Different Mechanisms of Intrinsically Disordered Proteins Interaction with Model Membranes. J. Phys. Chem. Lett. 2018, 9, 5125-5129. [CrossRef] [PubMed]

22. Jiang, T.; Sun, Q.; Chen, S. Oxidative stress: A major pathogenesis and potential therapeutic target of antioxidative agents in Parkinson's disease and Alzheimer's disease. Prog. Neurobiol. 2016, 147, 1-19. [CrossRef] [PubMed]

23. Mokhtari, Z.; Baluchnejadmojarad, T.; Nikbakht, F.; Mansouri, M.; Roghani, M. Riluzole ameliorates learning and memory deficits in Abeta25-35-induced rat model of Alzheimer's disease and is independent of cholinoceptor activation. Biomed. Pharmacother. Biomed. Pharmacother. 2017, 87, 135-144. [CrossRef] [PubMed]

24. Sciacca, M.F.M.; Romanucci, V.; Zarrelli, A.; Monaco, I.; Lolicato, F.; Spinella, N.; Galati, C.; Grasso, G.; D'Urso, L.; Romeo, M.; et al. Inhibition of Abeta Amyloid Growth and Toxicity by Silybins: The Crucial Role of Stereochemistry. ACS Chem. Neurosci. 2017, 8, 1767-1778. [CrossRef] [PubMed]

25. Malishev, R.; Shaham-Niv, S.; Nandi, S.; Kolusheva, S.; Gazit, E.; Jelinek, R. Bacoside-A, an Indian Traditional-Medicine Substance, Inhibits beta-Amyloid Cytotoxicity, Fibrillation, and Membrane Interactions. ACS Chem. Neurosci. 2017, 8, 884-891. [CrossRef] [PubMed]

26. Guo, H.; Cao, H.; Cui, X.; Zheng, W.; Wang, S.; Yu, J.; Chen, Z. Silymarin's Inhibition and Treatment Effects for Alzheimer's Disease. Molecules 2019, 24, 1748. [CrossRef] [PubMed]

27. Ghosh, A.; Pradhan, N.; Bera, S.; Datta, A.; Krishnamoorthy, J.; Jana, N.R.; Bhunia, A. Inhibition and Degradation of Amyloid Beta (Abeta40) Fibrillation by Designed Small Peptide: A Combined Spectroscopy, Microscopy, and Cell Toxicity Study. ACS Chem. Neurosci. 2017, 8, 718-722. [CrossRef] 
28. Cho, I.H. Effects of Panax ginseng in Neurodegenerative Diseases. J. Ginseng Res. 2012, 36, $342-353$. [CrossRef]

29. Kim, H.J.; Kim, P.; Shin, C.Y. A comprehensive review of the therapeutic and pharmacological effects of ginseng and ginsenosides in central nervous system. J. Ginseng Res. 2013, 37, 8-29. [CrossRef]

30. Tachikawa, E.; Kudo, K.; Harada, K.; Kashimoto, T.; Miyate, Y.; Kakizaki, A.; Takahashi, E. Effects of ginseng saponins on responses induced by various receptor stimuli. Eur. J. Pharmacol. 1999, 369, 23-32. [CrossRef]

31. Chen, L.M.; Zhou, X.M.; Cao, Y.L.; Hu, W.X. Neuroprotection of ginsenoside Re in cerebral ischemia-reperfusion injury in rats. J. Asian Nat. Prod. Res. 2008, 10, 439-445. [CrossRef] [PubMed]

32. Cho, W.C.; Chung, W.S.; Lee, S.K.; Leung, A.W.; Cheng, C.H.; Yue, K.K. Ginsenoside Re of Panax ginseng possesses significant antioxidant and antihyperlipidemic efficacies in streptozotocin-induced diabetic rats. Eur. J. Pharmacol. 2006, 550, 173-179. [CrossRef] [PubMed]

33. Xie, J.T.; Shao, Z.H.; Vanden Hoek, T.L.; Chang, W.T.; Li, J.; Mehendale, S.; Wang, C.Z.; Hsu, C.W.; Becker, L.B.; Yin, J.J.; et al. Antioxidant effects of ginsenoside Re in cardiomyocytes. Eur. J. Pharmacol. 2006, 532, $201-207$. [CrossRef] [PubMed]

34. Chen, F.; Eckman, E.A.; Eckman, C.B. Reductions in levels of the Alzheimer's amyloid beta peptide after oral administration of ginsenosides. FASEB J. Off. Publ. Fed. Am. Soc. Exp. Biol. 2006, 20, 1269-1271.

35. Kim, R.; Emi, M.; Tanabe, K. Role of mitochondria as the gardens of cell death. Cancer Chemother. Pharmacol. 2006, 57, 545-553. [CrossRef] [PubMed]

36. Martinou, J.C.; Youle, R.J. Mitochondria in apoptosis: Bcl-2 family members and mitochondrial dynamics. Dev. Cell 2011, 21, 92-101. [CrossRef]

37. Wang, J.Z.; Wang, Z.H. Senescence may mediate conversion of tau phosphorylation-induced apoptotic escape to neurodegeneration. Exp. Gerontol. 2015, 68, 82-86. [CrossRef]

38. Arunachalam, S.; Kim, S.Y.; Lee, S.H.; Lee, Y.H.; Kim, M.S.; Yun, B.S.; Yi, H.K.; Hwang, P.H. Davallialactone protects against adriamycin-induced cardiotoxicity in vitro and in vivo. J. Nat. Med. 2012, 66, 149-157. [CrossRef]

39. Chang, W.T.; Li, J.; Haung, H.H.; Liu, H.; Han, M.; Ramachandran, S.; Li, C.Q.; Sharp, W.W.; Hamann, K.J.; Yuan, C.S.; et al. Baicalein protects against doxorubicin-induced cardiotoxicity by attenuation of mitochondrial oxidant injury and JNK activation. J. Cell. Biochem. 2011, 112, 2873-2881. [CrossRef]

40. Liu, J.; Chang, F.; Li, F.; Fu, H.; Wang, J.; Zhang, S.; Zhao, J.; Yin, D. Palmitate promotes autophagy and apoptosis through ROS-dependent JNK and p38 MAPK. Biochem. Biophys. Res. Commun. 2015, 463, 262-267. [CrossRef]

41. Wang, Z.Y.; Liu, J.G.; Li, H.; Yang, H.M. Pharmacological Effects of Active Components of Chinese Herbal Medicine in the Treatment of Alzheimer's Disease: A Review. Am. J. Chin. Med. 2016, 44, 1525-1541. [CrossRef] [PubMed]

42. Yang, W.T.; Zheng, X.W.; Chen, S.; Shan, C.S.; Xu, Q.Q.; Zhu, J.Z.; Bao, X.Y.; Lin, Y.; Zheng, G.Q.; Wang, Y. Chinese herbal medicine for Alzheimer's disease: Clinical evidence and possible mechanism of neurogenesis. Biochem. Pharmacol. 2017, 141, 143-155. [CrossRef] [PubMed]

43. Kim, S.S.; Kang, M.S.; Lee, K.Y.; Lee, M.J.; Wang, L.; Kim, H.J. Therapeutic effects of mesenchymal stem cells and hyaluronic Acid injection on osteochondral defects in rabbits' knees. Knee Surg. Relat. Res. 2012, 24, 164-172. [CrossRef] [PubMed]

44. Ji, Z.N.; Dong, T.T.; Ye, W.C.; Choi, R.C.; Lo, C.K.; Tsim, K.W. Ginsenoside Re attenuate beta-amyloid and serum-free induced neurotoxicity in PC12 cells. J. Ethnopharmacol. 2006, 107, 48-52. [CrossRef]

45. Liu, Q.; Zhao, B. Nicotine attenuates beta-amyloid peptide-induced neurotoxicity, free radical and calcium accumulation in hippocampal neuronal cultures. Br. J. Pharmacol. 2004, 141, 746-754. [CrossRef]

46. Manczak, M.; Anekonda, T.S.; Henson, E.; Park, B.S.; Quinn, J.; Reddy, P.H. Mitochondria are a direct site of A beta accumulation in Alzheimer's disease neurons: Implications for free radical generation and oxidative damage in disease progression. Hum. Mol. Genet. 2006, 15, 1437-1449. [CrossRef]

47. Soga, M.; Matsuzawa, A.; Ichijo, H. Oxidative Stress-Induced Diseases via the ASK1 Signaling Pathway. Int. J. Cell Biol. 2012, 2012, 439587. [CrossRef]

48. Joshi, G.; Johnson, J.A. The Nrf2-ARE pathway: A valuable therapeutic target for the treatment of neurodegenerative diseases. Recent Pat. CNS Drug Discov. 2012, 7, 218-229. [CrossRef] 
49. Cui, G.; Luk, S.C.; Li, R.A.; Chan, K.K.; Lei, S.W.; Wang, L.; Shen, H.; Leung, G.P.; Lee, S.M. Cytoprotection of baicalein against oxidative stress-induced cardiomyocytes injury through the Nrf2/Keap1 pathway. J. Cardiovasc. Pharmacol. 2015, 65, 39-46. [CrossRef]

50. Ramsey, C.P.; Glass, C.A.; Montgomery, M.B.; Lindl, K.A.; Ritson, G.P.; Chia, L.A.; Hamilton, R.L.; Chu, C.T.; Jordan-Sciutto, K.L. Expression of Nrf2 in neurodegenerative diseases. J. Neuropathol. Exp. Neurol. 2007, 66, 75-85. [CrossRef]

51. Sarkar, B.; Dhiman, M.; Mittal, S.; Mantha, A.K. Curcumin revitalizes Amyloid beta (25-35)-induced and organophosphate pesticides pestered neurotoxicity in SH-SY5Y and IMR-32 cells via activation of APE1 and Nrf2. Metab. Brain Dis. 2017, 32, 2045-2061. [CrossRef] [PubMed]

52. Dai, Y.; Zhang, J.; Xiang, J.; Li, Y.; Wu, D.; Xu, J. Calcitriol inhibits ROS-NLRP3-IL-1beta signaling axis via activation of Nrf2-antioxidant signaling in hyperosmotic stress stimulated human corneal epithelial cells. Redox Biol. 2018, 21, 101093. [CrossRef] [PubMed]

53. Livak, K.J.; Schmittgen, T.D. Analysis of relative gene expression data using real-time quantitative PCR and the 2(-Delta Delta C(T)) Method. Methods 2001, 25, 402-408. [CrossRef] [PubMed]

54. Zhang, C.; Li, C.; Chen, S.; Li, Z.; Jia, X.; Wang, K.; Bao, J.; Liang, Y.; Wang, X.; Chen, M.; et al. Berberine protects against 6-OHDA-induced neurotoxicity in PC12 cells and zebrafish through hormetic mechanisms involving PI3K/AKT/Bcl-2 and Nrf2/HO-1 pathways. Redox Biol. 2017, 11, 1-11. [CrossRef] [PubMed]

Sample Availability: Not available. 